\title{
Identification of Genes Differentially Associated with Triple Negative Breast Cancers
}

\author{
Nissi Abraham, Sharon Kwende, Audrey Player* \\ Department of Biology, Texas Southern University, Houston, TX, USA
}

*Corresponding Author: Audrey Player, AlDepartment of Biology, Texas Southern University, Houston, TX, USA, Email: playeran@tsu.edu

\begin{abstract}
Triple negative breast cancers (TNBC) are characterized as negative for the expression of estrogen receptor, progesterone receptor and human epidermal growth factor receptor 2 genes. TNBC are more aggressive than other breast cancers and patients have a poorer five year survival rate. A significant number of studies have been performed in attempts to understand the biology of the cancers and biomarkers have been identified, still as of this date, genes that function as therapeutic targets have not been identified. This is largely due to the complexity of the disease. Although TNBC are classified as a single subtype, gene expression analyses show that it is a genetically heterogeneous disease. This makes it difficult to identify a specific gene-directed target that is unique to most TNBC. Investigators can only overcome the challenges associated with TNBC by continuing to characterize the cancers. In this article we will review the description of TNBC and outline the experimental approach utilized in our laboratory with the aim of further characterizing genes that might define TNBC patient samples and cell lines. Data are clear in demonstrating that not all TNBC are the same, and better understanding of these differences can explain why patients respond differently to particular therapies. Considering this, we will outline our approach to identifying genes that might potentially contribute to the TNBC heterogeneity. The expectation is that knowledge gleaned from our studies will aid in better understanding the genomes of TNBC.
\end{abstract}

Abbreviations: ABC-ATP Binding Cassette transporter, AR-Androgen receptor, BIRC3-Baculoviral IAP Repeat, ontaining 3, BL1-Basal-like 1, BL2-Basal-like 2, BLBC -Basal-like breast cancer, EGFR-Epidermal Growth Factor Receptor, EMT-Epithelial to mesenchymal transition, ER-Estrogen Receptor, ERK1Extracellular Signal-Regulated Kinase 1, ETS-1Erythroblastosis Virus E26, FN1-Fibronectin 1, FOXC1Forkhead Box C1, GATA3-GATA-Binding Factor 3, GSC-Goosecoidhomeobox, HCC70-Hamon Cancer Centre70 cell lines, HER2-Human epidermal growth factor receptor 2, IL32-Interleukin32, IL5-Interleukin5, IL6-Interleukin6, IL8-Interleukin8, IM- Immunomodulatory, JAK-Janus Kinase, KRT19-Keratin19, LARLuminal androgen receptor, M- Mesenchymal-like, MDA MB231-M.D. Anderson, Metastasis Breast cancer, MSL-Mesenchymal-stem like, MYBL1-Myeloblastosis Viral Oncogene, Homolog-Like 1, NFKB-Nuclear Factor Kappa B, PCR-Polymerase chain reaction, PD1-Programmed cell death 1, PDL-1-PD-ligand 1 , PDGF-Platelet Derived Growth Factor Subunit, PI3K-Phosphatidylinositol-4, 5-Bisphosphate 3-Kinase, PRProgesterone Receptor, PTX3-Pentraxin 3, STAT-Signal Transducer and Activator of Transcription, STRING-Search Tool for the Retrieval of Interacting Genes/Proteins, TGFb-Transforming Growth Factor Beta 1, TIMP1-TIMP Metallopeptidase Inhibitor 1, TMEM158-Transmembrane Protein 158, TNBC-Triple negative breast cancers, TNF-Tumor Necrosis Factor, Tspan13-Tetraspanin 13, VIM-Vimentin, ZEB1/2Zinc Finger E-Box Binding Homeobox 1

\section{INTRODUCTION AND BACKGROUND}

Breast cancer is the second leading cause of cancer death in women. The precise mechanisms leading to breast cancers are unknown, however both environmental and genetic factors are known to be contributing factors. There are different types of breast cancers based on pathological and molecular characteristics. Experiments designed to characterize the molecular aspects of cancers have led to identification of therapeutic targets and a better understanding of the biology of the cancers.

The number of molecular designations for the breast cancer subtypes have increased recently, nonetheless the core groupings continue to be luminal A, luminal B, HER2+, Basal-like breast cancer $(\mathrm{BLBC})$ and triple negative breast cancer (TNBC) $(1,2)$. Luminal A are characterized as positive for estrogen receptor gene (ER+) and progesterone receptor $(\mathrm{PR}+)$, and human epidermal growth factor receptor 2negative (HER2-). 
Luminal B are characterized as $\mathrm{ER}+, \mathrm{PR}+/-$ and HER2+. HER2 are characterized as enriched in HER2+ gene expression. BLBC are characterized as having low to PR- and ER/HER2+/- gene expression levels with increased expression of cytokeratin 5/6, 14 and 17basal cell gene markers(3). TNBC are characterized as ER-/PR-/HER- with varying levels of androgen receptor $(\mathrm{AR}+/-)$ gene expression. Data suggest the breast cancers develop from different progenitor cell types, accounting for their diverse genotypes. The luminal cancers are thought to originate from cells lining the luminal ducts, while the basal-like and triple negative cancers from the basal myoepithelial cells of the breast tissues(4). Related to their frequencies, luminal cancers occur at a rate of $60 \%$, compared to $25 \%$ for Her2 (+) and $15-$ $20 \%$ for BLBC and TNBC. Both TNBC and BLBC are more prevalent in younger patients and patients of African descent and Hispanic ethnicity compared to the other subtypes (1). TNBCs are often classified with the basal-like sub type, however TNBC and BLBC are very different cancers. Approximately 20\%-30\% of clinical TNBCs are not basal-like (5). The two cancer types have different risk factors and molecular profiles. For a more detailed comparison between TNBC and BLBC see the following reference (6).

\section{Heterogeneity of TNBC}

It is critically important to characterize TNBC because unlike receptor-positive patients, genes available for targeted therapy have not been identified. Receptor positive patients can be treated with therapies that target one or the other of the receptor genes; but because TNBC patients are negative for ER/PR/HER2 genes, surgery, radiation and chemotherapy are their only treatment options $(7,8)$. Genes useful as therapeutic targets for TNBC can only be identified by continued analyses of the genomes and transcriptomes of the cancers.

To date, many of the genes identified as biomarkers for TNBC and other cancers come from transcriptome analyses using DNA microarray gene chips. DNA microarray gene chips are essentially high-throughput microchips with the complementary genomic sequences attached(9) (10). DNA microarrays allow (a) the investigator to interrogate genes that are being expressed in a particular sample, at a defined interval, (b) gene expression profiles for different samples to be generated and compared utilizing bioinformatics methods, (c) for investigators to identify genes that are differentially associated between patient samples and (d) for investigators to identify cell signaling pathways that differ between particular sample types. Utilizing DNA microarray and hierarchical clustering methods, Lehmann et al (11) and others (12) (13) convincingly establish that TNBC does not represent a single group of patients but instead is a heterogeneous subtype representing diverse types of patients. Lehmann et al found that TNBC patient samples can be subdivided into six subclasses, based on their relationships to particular cellular processes. The investigators identified two different basal-like groups designated as basal-like 1 (BL1) and basal-like 2 (BL2), mesenchymal-like (M), mesenchymalstem like (MSL), immunomodulatory (IM) and a luminal androgen receptor (LAR) group. BL1 was defined by genes involved in cell cycle signaling and DNA division. BL2 was defined by genes related to growth factors signaling pathways, glycolysis and gluconeogenesis. IM subclass was defined by genes related to immune cell signaling processes including (but not limited to) cytokine, NFKB, TNF and JAK/STAT signaling pathways. $M$ was defined by genes involved in cell motility and differentiation. MSL subclass shared genes with $M$ subclass, but unique in that they included inositol phosphate metabolism, EGFR/PDGF, G-protein coupling, Erk1/2 signaling, ABC transporter and adipocytokine signaling pathway genes. The gene expression data associated with the particular subclass were utilized for selection of potential biomarkers, drug discovery and to identify potential therapeutic targets. Based on the signaling pathways found to be enriched in TNBC, the authors suggested targeting DNA damage and PI3K signaling pathways as therapeutic strategies.

Studies by Lehmann and other $(5,12,13)$ also support the contribution of immune-related genes in defining the heterogeneity of TNBC. In addition to their utility as biomarkers, immunerelated genes have been shown to correlate with tumor progression in TNBC. Emphasizing the role of immune-related mechanisms in cancers in general, recent applications using immunotherapeutic approaches are transforming how cancers are treated. Perhaps the most momentous achievements in cancer over the past 20 years are the discoveries of the programmed cell death 1 (PD1) and PD-ligand 1 (PDL-1) proteins and the subsequent description 
of their function in immunotherapy(14)(15). The PD1 protein is a receptor on $\mathrm{T}$ cells of the immune system and PDL-1 protein is overexpressed on some tumor cells. Drugs that target these proteins have proven to be an incredibly successful strategy in the fight against lung, bladder and skin cancers(16). Studies examining the potential role of PD1/PDL-1 genes in TNBC are ongoing. One such study in support of PDL-1 in TNBC was performed by Zhang et al (17). The researchers performed a meta-analyses of more than 2500 breast cancer patient samples. Data show PDL-1 protein expression correlations with TNBC, high histological grade and positive lymph node metastasis, confirming the role of immunerelated genes and processes in cancers. Recognizing the importance of the immunerelated genes in cancers, one aim of our studies is to characterize TNBC with a focus on identifying novel immune-related genes that are reliably differentially associated with the cancers.

\section{EXPERIMENTAL APPROACH FOR ANALYSES OF TNBC HETEROGENEITY}

Identification of distinct subpopulations of TNBC

\subsection{Brief Summary of Experimental Approach Utilized in Investigators Laboratory}

A primary focus of our laboratory is to further characterize TNBC with the overall goal of better understanding the cancers. One project is directed towards analyses of gene expression in TNBC cell lines and patient samples using bioinformatics-based methods. Similar to other investigators, we are attempting to define the heterogeneity of TNBC, however our experimental approach is different. An outline of our approach is given in Table1.

Table1. Outline of our experimental approach

\begin{tabular}{|c|}
\hline$S$ \\
\hline $\begin{array}{l}\text { Separate cell lines based on IL32-high vs IL32 low } \\
\text { gene expression levels }\end{array}$ \\
\hline $\begin{array}{l}\text { Compare } 2 \text { groups using T-test and Wilcoxon statistical } \\
\text { analyses }\end{array}$ \\
\hline $\begin{array}{l}\text { Identify genes differentially ex } \\
\text { IL32 low cell lines }\end{array}$ \\
\hline $\begin{array}{l}\text { Select using p Values } \stackrel{\downarrow}{<} 0.05 \text { with at least } 2 \text { fold } \\
\text { difference in gene levels }\end{array}$ \\
\hline $\begin{array}{l}\text { Perform enrichment analyses followed by experimental } \\
\text { (PCR) validation of } \\
\text { genes differentially expressed in IL32-high vs IL32-low }\end{array}$ \\
\hline
\end{tabular}

ARC Journal of Cancer Science
As summary, we previously retrieved TNBC DNA microarray datasets from Gene Expression Omnibus and found thatIL32 cytokine was differentially expressed in some, not all TNBC cell lines and patient samples (18). Cytokines are immune-modulating proteins involved in both immune and epithelial cell signaling events. Recognizing the importance and role of immune-related genes as both biomarkers and in tumor progression, we chose to better define IL32 gene expression in TNBC. In an attempt to identify genes that might possibly be dys regulated with IL32, the samples were grouped according to "those that express high IL32 levels compared to those that express lower to negligible IL32 levels'. The IL32-high and IL32-low groups were then compared using unsupervised bioinformatics-analyses(19) and a list of differentially expressed genes were generated. Gene Ontology analyses show that the differentially expressed genes included an enrichment of genes related to immune/defense processes and epithelial to mesenchymal (EMT) processes(20). Although our studies were the first to show differential expression of IL32 in a subpopulation of TNBC, other studies reported differential expression of IL6 (21) and IL8 (22) cytokines in subpopulations of TNBC. IL6 and IL8 genes were observed as differentially expressed in our dataset as well; both genes were observed as over-expressed in samples demonstrating high IL32 gene expression levels.

\subsection{Analysis of the Differentially Expressed Gene}

Following the outline given in Table 1, we identified what appears to be a list of genes that identify a subpopulation of TNBC, further characterizing the heterogeneity of the cancers. Our strongest gene candidates included IL32, MYBL1, ETS1, TMEM158, PTX3 and GATA3 genes. Detailed outline of the procedures, selection and validation of these genes were previously published (20). Gene Ontology analyses describe the genes as related to defense and immune responses (with p-value of 0.0001and a Bayes high confidence factor of 7) (23). IL32, MYBL1, ETS1, TMEM158, PTX3 and GATA3 genes were selected based on polymerase chain reaction (PCR) analyses and their performance following analyses of clinical patient samples. When our candidate genes are examined against $>150$ patient samples using hierarchical cluster and other bioinformatics methods, the genes appeared to stratify more than $60 \%$ of the TNBC patient samples, 
compared to non-tumor, luminal $\mathrm{A} / \mathrm{B}$, HER2 cancers and the remaining TNBC. Otherwise stated IL32 along with the other candidate genes were differentially associated with 'the $60 \%$ TNBC subpopulation'; possibly defining TNBC heterogeneity. IL32, MYBL1, ETS1, TMEM158, PTX3 appeared up-regulated in the TNBC subpopulation and GATA3 was downregulated in the same samples. The list of 5 genes were selected based on both PCR validation and their performance in clinical patient samples, but other than Gene Ontology, it is unclear at this point if there are functional relationships between them. Previous data does however show that the ETS1 transcription factor is a subtype classifier for basal cells and the GATA3 transcription factor is a luminal subtype classifier(24). These data validate our observation of ETS1 over-expression and GATA3 down-regulation in our TNBC study. In another study, experiments demonstrate synergism between ETS1 and GATA3 in transcriptional regulation of IL5 gene (25). No such functional relationship has been proposed for TNBC.

BIRC3 gene also appeared as differentially expressed in the TNBC subpopulation expressing high levels of IL32 gene. BIRC3 gene is a pro-survival gene which inhibits the apoptotic signaling pathway (26). At this point, it is unclear as to how or even whether BIRC3 contributes to survival of these particular TNBC. We are continuing to analyze these data.

\subsection{Continued Analysis of the Differentially Expressed Gene: Experimental Validation of EMT Related Genes}

We also observed statistical enrichment of EMT-related genes in the TNBC subpopulation expressing high IL32 gene levels. EMT is a genotypic process resulting in loss of epithelial characteristics including cellular polarity and adhesive properties. Cells that have undergone these processes increase their ability to migrate and subsequently invade the surrounding areas. Genes directly and indirectly related to the processes are referred to as EMT involved genes (27), (www.sabiosciences. com/rt_pcr_product/ HTML/PAHS-090Z.html).

TNBC are known to display EMT characteristics. Our study is not the first observation of the involvement of EMT in TNBC (28, 29). However, unlike previous studies, our observation is that TNBC that express IL32 also appear to be enriched in genes involved in EMT. These data suggest a correlation between EMT and IL32 gene expression in a subpopulation of TNBC. For the most part, the genes identified as differentially expressed in our analyses were not genes known to be transcriptional-drivers of the EMT process such as snail, twist, Zeb1/2, TGF $\beta$, Foxc1 or GSC. Except for ETS1 transcription factor, which is also an EMT gene, our datasets include genes that are both directly and indirectly associated with EMT processes. Demonstration of ETS1 expression in a subpopulation of TNBC is described in a previous publication (20). The EMT candidate gene list is summarized in Table 2.

Table2. Differentially expressed signature genes involved $n$ EMT processes.

The expression level refers to the gene expression in IL32-high TNBC as observed on original DNA microarray

\begin{tabular}{|l|l|l|}
\hline GENE & FUNCTION & Expression \\
\hline $\begin{array}{l}\text { Fibronectin } \\
\text { (FN1) }\end{array}$ & $\begin{array}{l}\text { Glycoprotein found in } \\
\text { extracellular matrix } \\
\text { involved in cell migration }\end{array}$ & +++ \\
\hline $\begin{array}{l}\text { Metalloprot } \\
\text { einase } \\
\text { (TIMP1) }\end{array}$ & $\begin{array}{l}\text { Promotes degradation of } \\
\text { extracellular matrix, cell } \\
\text { proliferation, apoptosis }\end{array}$ & +++ \\
\hline $\begin{array}{l}\text { Vimentin } \\
\text { (VIM) }\end{array}$ & $\begin{array}{l}\text { Maintains cell shape; } \\
\text { cytoskeletal involved in } \\
\text { migration and attachment }\end{array}$ & +++ \\
\hline $\begin{array}{l}\text { Keratin 19 } \\
\text { (KRT19) }\end{array}$ & $\begin{array}{l}\text { Intermediate filament } \\
\text { responsible for structural } \\
\text { integrity of cell }\end{array}$ & +++ \\
\hline $\begin{array}{l}\text { Tetraspanin } \\
\text { 13 }\end{array}$ & $\begin{array}{l}\text { Cell surface, } \\
\text { developmental, } \\
\text { activation } \\
\text { (Sspan13) mobility }\end{array}$ & ---- \\
\hline
\end{tabular}

The gene expression levels represent the levels observed in IL32-high expressing TNBC microarray datasets. All of the genes demonstrated high levels in IL32-high TNBC except Tspan13 which showed lower levels of the expression in the microarray datasets. For PCR experimental analyses, MDA MB231 cell line was chosen to represent IL32-high TNBC and HCC70 was chosen to represent IL32-low TNBC based on earlier observations (18). As a result the cell lines were utilized for validation of the EMT gene expression. Following experimental validation via PCR only 3 of the 5 genes validated, by demonstrating the same differential expression pattern as observed using the DNA microarray platform. FN1 and TIMP1 showed higher levels compared to Tspan13 which demonstrated lower levels in IL32 expressing cell lines. 


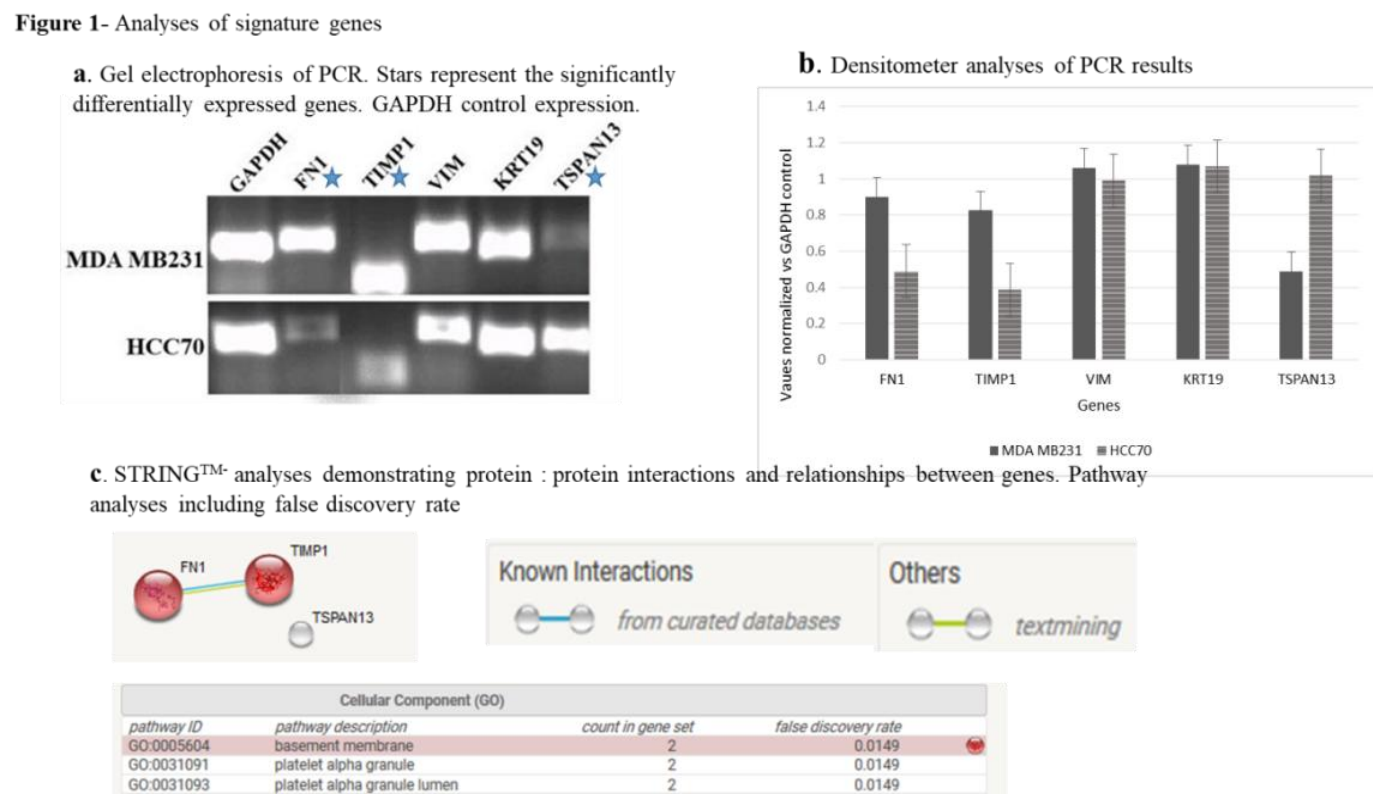

Figure1b. Represents the densitometer analyses of the PCR gel electrophoresis results. STRING ${ }^{T M}$ analyses (30)were used to demonstrate known protein: protein interactions between FN1, TIMP1 and Tspan13, and the false discovery rates (i.e., p-value 0.0149) associated with these interactions (Figure 1c). Combined these data suggest a correlation between IL32 and EMT expression in a subpopulation of TNBC, further supporting the complexity and heterogeneity of the cancers. Further analyses of the genes identified here can substantiate their utility as reliable biomarkers associated with TNBC.

\section{CONCLUSiON}

It is clear that TNBC is a complex disease. Our aim is continue analyses of both TNBC cell lines and patient samples in an effort to identify yet unknown biomarkers that can be studied for clinical relevance as potential therapeutic targets. We chose to use the DNA microarray mainly because the platform allows for interrogation of known genes and signaling pathways. We describe an experimental approach aimed at identifying genes that define TNBC. The experimental approach appears to be successful, in that novel genes related to the cancers have been identified. Analyses of the results are ongoing and should contribute to future discussions involving TNBC.

\section{ACKNOWLEDGEMENTS}

The authors would like to thank the RCMI which supplied funding during the period in which this article was written. The authors would also like to thank the Departments of Biology and Environmental Toxicology for their continued financial support.

\section{REFERENCES}

[1] Carey LA, Perou CM, Livasy CA, Dressler LG, Cowan D, Conway K, et al. Race, breast cancer subtypes, and survival in the Carolina Breast Cancer Study. Jama. 2006 Jun 07; 295(21):2492-502. PubMed PMID: 16757721. Epub 2006/06/08. eng.
[2] Yanagawa M, Ikemot K, Kawauchi S, Furuya T, Yamamoto S, Oka M, et al. Luminal A and luminal B (HER2 negative) subtypes of breast cancer consist of a mixture of tumors with different genotype. BMC research notes. 2012 Jul 25; 5:376. PubMed PMID: 22830453. Pubmed Central PMCID: PMC3413599. Epub 2012/07/27. eng.

[3] Seal MD, Chia SK. What is the difference between triple-negative and basal breast cancers? Cancer journal (Sudbury, Mass). 2010 Jan-Feb; 16(1):12-6. PubMed PMID: 20164685. Epub 2010/02/19. eng.

[4] Kao J, Salari K, Bocanegra M, Choi YL, Girard L, Gandhi J, et al. Molecular profiling of breast cancer cell lines defines relevant tumor models and provides a resource for cancer gene discovery. PloS one. 2009 Jul 03; 4(7):e6146. PubMed PMID: 19582160. Pubmed Central PMCID: PMC2702084. Epub 2009/07/08. eng.

[5] Lehmann BD, Pietenpol JA. Clinical implications of molecular heterogeneity in triple negative breast cancer. Breast (Edinburgh, Scotland). 2015 Nov; 24 Suppl 2:S36-40. PubMed PMID: 26253813. Pubmed Central PMCID: PMC4641762. Epub 2015/08/09. eng.

[6] Goldhirsch A, Winer EP, Coates AS, Gelber RD, Piccart-Gebhart M, Thurlimann B, et al. personalizing the treatment of women with early breast cancer: highlights of the St Gallen International Expert Consensus on the Primary Therapy of Early Breast Cancer 2013. Annals of oncology: official journal of the European 
Society for Medical Oncology. 2013 Sep; 24(9):2206-23. PubMed PMID: 23917950. Pubmed Central PMCID: PMC3755334. Epub 2013/08/07. eng.

[7] Bartsch R, Bergen E. ASCO 2017: highlights in breast cancer. Memo. 2017; 10(4):228-32. PubMed PMID: 29250202. Pubmed Central PMCID: PMC5725517. Epub 2017/12/19. eng.

[8] Exner R. Local therapies for breast cancer. Memo. 2017; 10(3):181-4. PubMed PMID: 28989544. Pubmed Central PMCID: PMC5605588. Epub 2017/10/11. eng.

[9] Perou CM, Borresen-Dale AL. System's biology and genomics of breast cancer. Cold Spring Harbor perspectives in biology. 2011 Feb 01; 3(2). PubMed PMID: 21047916. Pubmed Central PMCID: PMC3039533. Epub 2010/11/05. eng.

[10] Brennan DJ, Kelly C, Rexhepaj E, Dervan PA, Duffy MJ, Gallagher WM. Contribution of DNA and tissue microarray technology to the identification and validation of biomarkers and personalised medicine in breast cancer. Cancer genomics \& proteomics. 2007 MayJun;4(3):121-34. PubMed PMID: 17878516. Epub 2007/09/20. eng.

[11] Lehmann BD, Jovanovic B, Chen X, Estrada MV, Johnson KN, Shyr Y, et al. Refinement of Triple-Negative Breast Cancer Molecular Subtypes: Implications for Neoadjuvant Chemotherapy Selection. PloS one. 2016; 11(6):e0157368. PubMed PMID: 27310713. Pubmed Central PMCID: PMC4911051. Epub 2016/06/17. eng.

[12] Pareja F, Geyer FC, Marchio C, Burke KA, Weigelt B, Reis-Filho JS. Triple-negative breast cancer: the importance of molecular and histologic subtyping, and recognition of lowgrade variants. NPJ breast cancer. 2016; 2:16036. PubMed PMID: 28721389. Pubmed Central PMCID: PMC5515338. Epub 2017/07/20. eng.

[13] Ocana A, Pandiella A. Targeting oncogenic vulnerabilities in triple negative breast cancer: biological bases and ongoing clinical studies. Oncotarget. 2017 Mar 28; 8(13):22218-34. PubMed PMID: 28108739. Pubmed Central PMCID: PMC5400659. Epub 2017/01/22. eng.

[14] Ichikawa M, Chen L. Role of B7-H1 and B7H4 molecules in down-regulating effector phase of T-cell immunity: novel cancer escaping mechanisms. Frontiers in bio science : a journal and virtual library. 2005 Sep 01; 10:2856-60. PubMed PMID: 15970540. Epub 2005/06/23. eng.

[15] Mittal D, Gubin MM, Schreiber RD, Smyth MJ. New insights into cancer immunoediting and its three component phases--elimination, equilibrium and escape. Current opinion in immunology. 2014 Apr; 27:16-25. PubMed PMID: 24531241. Pubmed Central PMCID: PMC4388310. Epub 2014/02/18. eng.

[16] Wang X, Teng F, Kong L, Yu J. PD-L1 expression in human cancers and its association with clinical outcomes. OncoTargets and therapy. 2016; 9:5023-39. PubMed PMID: 27574444. Pubmed Central PMCID: PMC4990391. Epub 2016/08/31. eng.

[17] Zhang M, Sun H, Zhao S, Wang Y, Pu H, Wang $\mathrm{Y}$, et al. Expression of PD-L1 and prognosis in breast cancer: a meta-analysis. Oncotarget. 2017 May 09; 8(19):31347-54. PubMed PMID: 28430626. Pubmed Central PMCID: PMC5458212. Epub 2017/04/22. eng.

[18] Player A, Oguamanam T, Okanmelu J, Burrell K, Hollomon M. Preliminary characterization of IL32 in basal-like/triple negative compared to other types of breast cell lines and tissues. BMC research notes. 2014 Aug 07; 7:501. PubMed PMID: 25100201. Pubmed Central PMCID: PMC4132244. Epub 2014/08/08. eng.

[19] Greene JM, Asaki E, Bian X, Bock C, Castillo $\mathrm{S}$, Chandramouli $\mathrm{G}$, et al. The NCI/CIT microArray database (mAdb) system bioinformatics for the management and analysis of Affymetrix and spotted gene expression microarrays. AMIA Annual Symposium proceedings AMIA Symposium. 2003:1066. PubMed PMID: 14728569. Pubmed Central PMCID: PMC1479987. Epub 2004/01/20. eng.

[20] Player A, Abraham N, Burrell K, Bengone IO, Harris A, Nunez L, et al. Identification of candidate genes associated with triple negative breast cancer. Genes \& cancer. 2017 Jul; 8(78):659-72. PubMed PMID: 28966727. Pubmed Central PMCID: PMC5620011. Epub 2017/10/03. eng.

[21] Fertig EJ, Lee E, Pandey NB, Popel AS. Analysis of gene expression of secreted factors associated with breast cancer metastases in breast cancer subtypes. Scientific reports. 2015 Jul 15; 5:12133. PubMed PMID: 26173622. Pubmed Central PMCID: PMC4648401. Epub 2015/07/16. eng.

[22] Rody A, Karn T, Liedtke C, Pusztai L, Ruckhaeberle E, Hanker L, et al. A clinically relevant gene signature in triple negative and basal-like breast cancer. Breast cancer research: BCR. 2011 Oct 06; 13(5):R97. PubMed PMID: 21978456. Pubmed Central PMCID: PMC3262210. Epub 2011/10/08. eng.

[23] Chang JT, Nevins JR. GATHER: a systems approach to interpreting genomic signatures. Bioinformatics (Oxford, England). 2006 Dec 1; 22(23):2926-33. PubMed PMID: 17000751. Epub 2006/09/27. eng. 
[24] Charafe-Jauffret E, Ginestier C, Monville F, Finetti P, Adelaide J, Cervera N, et al. Gene expression profiling of breast cell lines identifies potential new basal markers. Oncogene. 2006 Apr 6; 25(15):2273-84. PubMed PMID: 16288205. Epub 2005/11/17. eng.

[25] Wang J, Shannon MF, Young IG. A role for Ets1, synergizing with AP-1 and GATA-3 in the regulation of IL-5 transcription in mouse Th2 lymphocytes. International immunology. 2006 Feb; 18(2):313-23. PubMed PMID: 16373364. Epub 2005/12/24. eng.

[26] Takahashi R, Deveraux Q, Tamm I, Welsh K, Assa-Munt N, Salvesen GS, et al. A single BIR domain of XIAP sufficient for inhibiting caspases. The Journal of biological chemistry. 1998 Apr 03; 273(14):7787-90. PubMed PMID: 9525868. Epub 1998/05/09. eng.

[27] Zhao M, Kong L, Liu Y, Qu H. dbEMT: an epithelial-mesenchymal transition associated gene resource. Scientific reports. 2015 Jun 23; 5:11459.
PubMed PMID: 26099468. Pubmed Central PMCID: PMC4477208. Epub 2015/06/24. eng.

[28] Ahn SG, Kim SJ, Kim C, Jeong J. Molecular Classification of Triple-Negative Breast Cancer. Journal of breast cancer. 2016 Sep; 19(3):223-30. PubMed PMID: 27721871. Pubmed Central PMCID: PMC5053306. Epub 2016/10/11. eng.

[29] Jiang Z, Jones R, Liu JC, Deng T, Robinson T, Chung PE, et al. RB1 and p53 at the crossroad of EMT and triple-negative breast cancer. Cell cycle (Georgetown, Tex). 2011 May 15; 10(10):1563-70. PubMed PMID: 21502814. Epub 2011/04/20. eng.

[30] Szklarczyk D, Morris JH, Cook H, Kuhn M, Wyder S, Simonovic M, et al. The STRING database in 2017: quality-controlled proteinprotein association networks, made broadly accessible. Nucleic acids research. 2017 Jan 04; 45(D1):D362-D8. PubMed PMID: 27924014. Pubmed Central PMCID: PMC5210637. Epub 2016/12/08. eng.

Citation: Nissi Abraham, Sharon Kwende, Audrey Player. Identification of Genes Differentially Associated with Triple Negative Breast Cancers. ARC Journal of Cancer Science 2017; 3(2):1-7. DOI: http://dx.doi.org/10.20431/2455-6009.0302001

Copyright: (C) 2017 Authors. This is an open-access article distributed under the terms of the Creative Commons Attribution License, which permits unrestricted use, distribution, and reproduction in any medium, provided the original author and source are credited. 